\title{
Repensando la educación rural en una zona transfronteriza entre Costa Rica y Nicaragua: El caso de la Región Huetar Norte (RHN)
}

\author{
Rethinking Education in a Rural Border Area Between Costa Rica and Nicaragua: The Case \\ of Northern Huetar Region (RHN)
}

\section{Repensando a educação rural numa área de fronteira entre Costa Rica e Nicarágua: O caso da Região Huetar Norte}

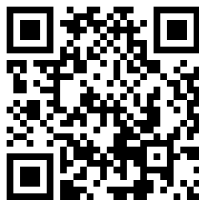

\author{
Erick Francisco Salas-Acuña ${ }^{1}$ \\ Instituto Tecnológico de Costa Rica \\ San Carlos, Costa Rica \\ esalas@itcr.ac.cr
}

\author{
Recibido • Received • Recebido: 04 / 08 / 2016 \\ Corregido • Revised • Revisado: 05 / 02 / 2018 \\ Aceptado • Accepted • Aprovado: 22/ 02 / 2018
}

\begin{abstract}
Resumen: Este ensayo reflexiona sobre la educación rural en una zona transfronteriza de Costa Rica con el objetivo de plantear la necesidad de promover procesos educativos que respondan a las condiciones de este territorio. Para ello se problematizan conceptos tales como ruralidad, frontera e interculturalidad, para luego describir la conformación histórica de esta región, poniendo énfasis en el protagonismo de poblaciones nicaragüenses en la colonización de los territorios del norte, los cuales constituyen un espacio de identidad cultural producto de la interconexión entre ambos países. Se parte de que la inclusión de esta "cultura trasfronteriza" constituye un reto pendiente dentro de las políticas educativas nacionales, por lo que se argumenta a favor de una educación intercultural que contemple las experiencias binacionales de este territorio, con el fin de contribuir al intercambio, la interacción y la cooperación entre ambas fronteras.
\end{abstract}

Palabras claves: Educación; ruralidad; zona trasfronteriza; interculturalidad.

\begin{abstract}
This essay discusses education in a rural cross-border area of Costa Rica, the Región Huetar Norte (Northern Huetar Region). It aims to raise the need of promoting educational processes that respond to the conditions of this territory. To do this, concepts such as rurality, border, and interculturality are problematized. Later comes a description of the historical conformation of this region, emphasizing the important role of Nicaraguan populations in the colonization of the northern territories; these territories constitute a space of cultural identity favored by the interconnection between both countries. Under the assumption that the inclusion of this "cross-border culture" constitutes a pending challenge for national educational policies, the essay argues for an intercultural education that contemplates the binational experiences of this territory in order to contribute to the exchange, the interaction and cooperation between both borders.
\end{abstract}

Keywords: Education; rurality; border area; interculturality.

\footnotetext{
${ }^{1}$ Profesor del Instituto Tecnológico de Costa Rica, sede San Carlos. Egresado de la Maestría en Educación Rural Centroamericana.
} 
doi: http://dx.doi.org/10.15359/ree.22-2.18

URL: http://www.una.ac.cr/educare

CORREO: educare@una.cr

\begin{abstract}
Resumo: Este ensaio reflete sobre a educação rural em uma área de fronteira da Costa Rica, a fim de apresentar a necessidade de promover processos educacionais que atendam às condições deste território. Para isso, conceitos como ruralidade, fronteira e interculturalidade são problematizados, para em seguida, descrever a formação histórica desta região, enfatizando o papel das populações da Nicarágua na colonização dos territórios do norte, que constituem um espaço de identidade cultural, resultado da união entre estes dois países. Supõe-se que a inclusão dessa "cultura interfronteira" é um desafio pendente nas políticas nacionais de educação, motivando um argumento em favor de uma educação intercultural que inclui experiências binacionais deste território, a fim de contribuir para a troca, interação e cooperação entre as duas fronteiras.
\end{abstract}

Palavras-chave: educação, ruralidade, área de fronteira, interculturalidade.

\title{
La reconfiguración del espacio rural
}

Uno de los principales retos de la educación en Centroamérica, además de mejorar la cobertura, calidad y permanencia de estudiantes en las aulas, tiene que ver con reducir la brecha entre la educación de zonas rurales y urbanas ${ }^{2}$. Si bien existe un creciente interés en repensar los procesos educativos en zonas rurales, lo cierto es que a nivel regional son pocas las políticas nacionales orientadas a proponer programas educativos específicos para la ruralidad, tal y como señalan Angulo, Morera y Torres (2010, p. 46): “En términos generales y con algunas salvedades, a pesar de que se explicita el interés por cerrar la brecha de calidad existente entre lo rural y lo urbano, ampliando la cobertura y fortaleciendo la educación en ... áreas rurales, sin embargo, se adolece de políticas y medidas concretas en procurar de cerrar tales brechas". Esto es significativo en una región que en materia educativa muestra serios problemas en cuanto a la integración y planificación regional, así como en la asignación de recursos para el fortalecimiento de la educación rural, lo que sin duda repercute en las condiciones de vida de sus habitantes. A nivel regional, por ejemplo, la Universidad Nacional de Costa Rica es la única institución de educación superior que investiga y forma docentes en materia de educación rural (Angulo et al., 2010).

Centroamérica se caracteriza por ser una región en donde la desigualdad y la exclusión social producen, como consecuencia, altos índices de inmigración intra y extraregional, la cual se estima entre un 10 y un 12 por ciento de la población (Sandoval, 2015). Se trata de un resultado de las políticas neoliberales en la región que, como bien señala Morales (2007), arrastra a un grupo importante de personas centroamericanas a emigrar ante "la desnacionalización y desvanecimiento de las economías tradicionales" (p. 326).

Las comunidades rurales, donde por lo general se encuentran poblaciones que subsisten a partir de actividades como la ganadería y la agricultura, son las que ven más vulnerados sus estilos de vida, lo cual las impulsa a emigrar en busca de mejores condiciones. Si a esto se le

${ }^{2}$ Para más información puede consultarse el documento Exclusión educativa y laboral de la población de 15 a 24 años en Centroamérica (Programa Estado de la Nación en Desarrollo Humano Sostenible [Costa Rica], 2015).

2 
suma el hecho de que en estos territorios también se encuentran ubicados grupos étnicos que históricamente han sido objeto de discriminación, exclusión y abandono por parte de los Estados, el problema adquiere dimensiones aún mayores. De hecho, según el Estado de la Región (Programa Estado de la Nación en Desarrollo Humano Sostenible [Costa Rica], 2015) vivir en una zona rural constituye el tercer factor de exclusión a nivel regional, pues aumenta el riesgo relativo de exclusión en 1,5 veces.

En los últimos años, la progresiva penetración de las vías de comunicación, los procesos migratorios, la influencia cada vez mayor de los medios de comunicación masiva y la presencia de empresas transnacionales han jugado un papel importante en la transformación de medios de producción tradicionales, lo que ha repercutido en los estilos de vida de las personas. No se trata ya de aquellos territorios aislados que se creían podían permanecer ajenos a las transformaciones en los centros del país, y cuya identidad se asumía como estática y homogénea. Ahora las poblaciones de las comunidades rurales ven cada vez más coartados sus estilos de vida a causa de estos procesos, situación que se traduce en condiciones de desapego, pérdida de vínculos de solidaridad, inmigración, entre otras, que amenazan cada vez más la sostenibilidad y futuro de estas comunidades.

Los efectos de estas políticas internacionales de globalización, en los países mal llamado (sic) en vías de desarrollo han ocasionado la emergencia de "una nueva ruralidad", cada vez menos agraria, más moderna, teniendo en la mayoría de los países como consecuencia una mayor exclusión de las clases trabajadoras de sus lugares de nacimiento, produciendo oleadas de inmigración hacia el extranjero o hacia ciudades más cosmopolitas, solo por nombrar una (sic) de ellas. (Vidal, Torres, Cerdas y Vargas, 2015, p. 45)

Según Vidal et al. (2015), tres son los campos en los que ha impactado la "modernización" del campo: en lo territorial, la construcción de vías de comunicación, la inversión en infraestructura y la llegada de las nuevas tecnologías han propiciado la creación de proyectos agrícolas, agroindustriales y turísticos; en el trabajo, dado que la transformación del territorio genera la demanda de mano de obra con nuevas habilidades para emplearse en los grandes hoteles y empresas; $y$, por último, en lo cultural, ya que "los valores tradicionales han cedido su importancia ante nuevas tendencias de comportamiento mundiales..." (p. 50). Esto ha producido que la frontera entre lo urbano y lo rural, que antes separaba dos realidades que se suponían de naturaleza diversa, se torne cada vez más difusa.

Asimismo, hay que remarcar que, en el contexto de la llamada "globalización" y la aplicación de los programas de ajuste, los espacios rurales cambian de manera acelerada, haciéndose cada vez ... complejos y heterogéneos, por lo que algunas de las características tradicionalmente atribuidas al entorno rural, ya no corresponden en su totalidad con el nuevo escenario. (Angulo et al., 2010, p. 10) 
doi: http://dx.doi.org/10.15359/ree.22-2.18

URL: http://www.una.ac.cr/educare

CORREO: educare@una.cr

Esta situación demanda que se realicen esfuerzos orientados a revalorizar lo rural, pero no ya desde miradas tradicionales que redundan en las limitaciones del campo en comparación con la ciudad, sino desde aproximaciones que reconozcan tanto las riquezas de estos territorios como las nuevas condiciones que los caracterizan. El problema, sin embargo, radica en que aún prevalecen visiones acerca de lo rural que poco se ajustan a las nuevas dinámicas de estas comunidades, lo que puede verse en el fracaso de muchas de las iniciativas gubernamentales, cuyos resultados no logran traducirse en mejores condiciones de vida para las personas.

Aunque los desarrollos teóricos conceptuales y empíricos que dan soporte al concepto de territorio rural no son de reciente aparición sino que han sido formulados, desarrollados e instrumentados desde décadas atrás, la pertinencia de una nueva concepción se basa en la evidencia de que la mayor parte de las políticas públicas que se están aplicando en este momento para los territorios rurales de nuestra América, contemplan muy parcialmente los elementos que constituyen esta visión integral de orden regional y territorial. (Echeverri y Ribero, 2002, pp. 27-28)

En estas aproximaciones existe un predominio de lo económico por sobre otros aspectos que justifican la intervención de los gobiernos en las zonas rurales solo en función de aumentar los procesos productivos e incentivar la inversión de capital extranjero para generar empleo, obviando las repercusiones en las dinámicas sociales y culturales de los pueblos, que traen consigo estas transformaciones.

Una expresión del predominio de las visiones economicistas es el énfasis que se le ha dado a la idea de convertir en capitales cada una de las dimensiones ... del ser humano: más que personas o sociedad, somos capital humano; más que patrimonio y riqueza natural, somos capital natural; más que formas de organización, somos capital social. Si bien estas condiciones ayudan a entender y a empujar procesos de desarrollo ... del ser humano que se mueve por motivaciones no exclusivamente económicas. (Echeverri y Ribero, 2002, p. 28)

La historia, la tradición y la cultura son los elementos constitutivos de la ruralidad, tal y como lo indica Echeverri y Ribero (2002): "La ruralidad es una condición característica asociada a territorios, que tienen en esencia una construcción de orden histórico y social, como procesos prolongados de conformación de sociedades y organizaciones territoriales" (p. 30). Por tanto, estos territorios han devenido en la construcción de cosmovisiones, lenguajes, valores, etc. que otorgan sentidos de pertenencia e identidad. De ahí que comprender lo rural implique, sobre todo, comprender lo que sucede en el seno de las relaciones sociales. 
El problema de los procesos de desarrollo que tienden a enfatizar los aportes económicos es que esconden grandes pérdidas de orden social y cultural. Superar las limitaciones de estas aproximaciones es lo que buscan los trabajos que proponen la necesidad de repensar la ruralidad desde los territorios. Estas aproximaciones proponen revalorar estos elementos incorporándolos a las políticas de desarrollo rural y de fortalecimiento, protección y conservación, superando la visión dicotómica entre lo rural y lo urbano que predomina en los estudios sobre el tema.

Todo esto vuelve pertinente volver la mirada a las zonas rurales; pero, sobre todo, a lo que los discursos sobre lo rural han construido en torno a estos territorios, los cuales resultan insuficientes para entender la complejidad que albergan estos territorios en la actualidad. Hoy, más que nunca, las zonas rurales requieren no solo de una revalorización, sino de una reconceptualización que permita aprender la complejidad de las condiciones que enfrentan muchos de los territorios rurales en la actualidad, sobre todo porque, detrás de toda esta discusión, lo que existe es la preocupación por la imposibilidad del disfrute de una ciudadanía social, así como de la desigualdad en el desarrollo de los territorios, aspectos fundamentales en una sociedad democrática (Mora, 2013).

Comprender las transformaciones que experimentan los contextos rurales se convierte, así, en una posibilidad para contener "el desmantelamiento de las economías locales y regionales"a costa de políticas de la globalización neoliberal (Sandoval, 2015, p. xxii). En este contexto, si bien no puede caerse en el error de considerar la educación como la única salida a estos problemas, esta se posiciona como un derecho humano elemental que habilita la consecución de otros derechos (Méndez, 2015). Como señala este autor, "la educación no puede por sí mismo lograr transformaciones profundas ya que los sistemas políticos, económicos y culturales arraigados en Centroamérica tienen como fundamento la exclusión social" (Méndez, 2015, p. 24). Por ello, en el contexto centroamericano, la educación cobra relevancia como una herramienta política de inclusión y resistencia a las desigualdades económicas, sociales y culturales que predominan actualmente en la región

El problema, sin embargo, radica en que las políticas educativas no suelen ajustarse en la mayoría de los casos a las características de lo rural relacionadas, por ejemplo, con la diversidad cultural, étnica y lingüística de muchos de estos pueblos que habitan en las zonas rurales. La gran diversidad geográfica, cultural, étnica y lingüística de Centroamérica, sin embargo, demanda la creación de procesos educativos diferenciados que se ajusten a las distintas realidades que conforman los territorios rurales, con el fin de evitar una educación homogeneizante que diluya los estilos de vida de estas comunidades. Esta preocupación pasa por la reflexión sobre la ruralidad y los cambios a los que esta ha sido sometida a raíz de las transformaciones causadas por los procesos de globalización y el modelo neoliberal de desarrollo implementado a partir de los años ochenta en la región, así como por el cuestionamiento mismo que se tiene 
doi: http://dx.doi.org/10.15359/ree.22-2.18

URL: http://www.una.ac.cr/educare

CORREO: educare@una.cr

sobre la conformación de estos territorios. ${ }^{3}$ En otras palabras, se trata de repensar las distintas regiones a través de los países de forma diferenciada, reconociendo que existe una diversidad de "realidades" que superan la vieja separación entre lo urbano y lo rural, y que requieren de nuevas miradas más acordes con las especificidades históricas, culturales, sociales y económicas propias de cada región. ${ }^{4}$

Con el propósito de asumirse desde esta diversidad, países como Costa Rica han realizado algunos esfuerzos en materia de jurisprudencia nacional para garantizar el derecho a la diferencia de sus distintas poblaciones. El año 2015, por ejemplo, el gobierno costarricense modificó el Artículo 1 de su Constitución Política para declararse una república democrática, libre, independiente, multiétnica y pluricultural (Asamblea Legislativa de la República de Costa Rica, 2015), hecho sin duda significativo para un país cuyo imaginario nacional ha excluido estructuralmente a un gran porcentaje de costarricenses, como ha sido el caso de las poblaciones indígenas. Cabe aclarar, sin embargo, que mucho antes de esta modificación ya el Ministerio de Educación Pública (MEP) venía realizando una serie de esfuerzos sostenidos que pretendían incorporar el componente intercultural tanto a nivel administrativo como curricular. La inclusión de la temática indígena, afrodescendiente y migratoria dentro de los currículos constituye algunos de los principales esfuerzos realizados hasta la fecha. No obstante, aún está pendiente comprobar hasta qué punto estos esfuerzos se han podido materializar en acciones concretas dentro de las aulas. Esto es un problema en tanto lo que interesa, a fin de cuentas, es incidir en la conformación de discursos más inclusivos y respetuosos de la diversidad.

La Región Huetar Norte (RHN) de este país, por ejemplo, se caracteriza no solo por la presencia de uno de los grupos indígenas más importantes del país, los malekus, sino también por su condición transfronteriza, lo que le impone el desafío de luchar por trascender el discurso

\footnotetext{
3 "En el modelo neoliberal se concibe que la educación debe someterse a la libre competencia y por lo tanto, que los conocimientos, las capacidades adquiridas y las habilidades se deben someter al juego de la oferta y la demanda." (Angulo et al., 2010, 35). "Los efectos de estas políticas internacionales de globalización, en los países mal llamados en vías de desarrollo han ocasionado la emergencia de 'una nueva ruralidad', cada vez menos agraria, más moderna, teniendo en la mayoría de los países como consecuencia una mayor exclusión de las clases trabajadoras de sus lugares de nacimiento, produciendo oleadas de migración hacia el extranjero o hacia ciudades más cosmopolitas, solo por nombrar una de ellas" (Vidal, Torres, Cerdas y Vargas, 2015, 45).

${ }^{4}$ León (2015, xxiv) sostiene que existe una tendencia analítica en la que"la experiencia y sensibilidad vallecentraleña es proyectada al resto del país como si fuera la única existente", y cuya consecuencia ha sido la desaparición de las "diferencias territoriales que marcan los contornos políticos de país", "el efecto de presentar como 'nacional' una narrativa particular, pero dominante, generada fundamentalmente desde el Valle Central", y el "dar respuestas satisfactorias al qué pasó, pero claras limitaciones para contestar el cómo, adónde y para quién". "En resumidas cuentas, el resultado es una narrativa histórica francamente chata, donde las experiencias diferenciadas de las distintas posiciones de clase son diluidas hasta disolverse y donde las desigualdades existentes entre los distintos espacios concretos de país tienen a ser invisibilizadas por la dominante escala del 'Estado Nación"'.
} 
nacionalista para construir esfuerzos orientados a incluir estas poblaciones dentro de políticas educativas más acordes con las dinámicas binacionales propias de este territorio. El problema radica en que las políticas educativas en el contexto costarricense tienden a imponer un currículo escolar homogeneizante que se proyecta desde el centro del país hacia las periferias, excluyendo las diferencias culturales y territoriales de las poblaciones rurales. En este sentido resulta importante realizar esfuerzos orientados a promover una educación más inclusiva y contextualizada de acuerdo con las experiencias de vida que favorezca estas poblaciones.

El objetivo de este ensayo es proponer la necesidad de reconocer el protagonismo histórico de poblaciones nicaragüenses en la colonización de los territorios del norte, los cuales constituyen en la actualidad un espacio de identidad cultural producto de la interconexión entre ambos países, con el fin de reconocer que la inclusión de esta "cultura trasfronteriza" constituye un reto pendiente dentro de las políticas educativas nacionales. Por ello se argumenta a favor de una educación intercultural que contemple las experiencias binacionales de este territorio, con el fin de contribuir al intercambio, la interacción y la cooperación entre ambas fronteras.

\section{Conformación histórica de la Región Huetar Norte (RHN)}

La RHN es producto de una invención político-administrativa que se establece a partir de 1986, década en que se consolidan las seis regiones en que se divide el país y se empiezan a crear las primeras oficinas regionales que buscaban pensar el país regionalmente para así descentralizarlo. ${ }^{5}$ Con el paso del tiempo, esta y otras regiones han sufrido ajustes que han venido muchas veces aumentar la complejidad de territorios que componen estas regiones. En todos estos casos, como se dijo en un inicio, lo que ha caracterizado estos procesos de regionalización es el predominio de decisiones de corte político-administrativas sobre otras de índole cultural o productivo, lo que ha significado un problema para la comprensión de los territorios diversos que se agrupan en una misma región.

La RHN, por ejemplo, está conformada por los cantones de San Carlos, Upala (que antes de 1985 pertenecía a la Región Chorotega), Los Chiles, Guatuso, Sarapiquí, y los distritos de Peñas Blancas (San Ramón), y Río Cuarto (Grecia) ${ }^{6}$. Se trata, en esencia, de territorios diversos que, incluso desde sus dinámicas productivas, han demostrado a lo largo de la historia que no constituyen un espacio homogéneo, sino una región cargada de especificidades y dinámicas complejas.

El proceso de colonización de esta región, que inicia a mediados del siglo XIX, es patente de las particularidades que incluso hoy caracterizan la región. Los principales focos de penetración han dado como resultado una región tripartita que comprende los territorios del norte de la

\footnotetext{
${ }^{5}$ Sobre el proceso de regionalización administrativa costarricense puede verse León (2015).

${ }^{6}$ Para aspectos generales de la región ver MIDEPLAN (2014).
} 
doi: http://dx.doi.org/10.15359/ree.22-2.18

URL: http://www.una.ac.cr/educare

CORREO: educare@una.cr

región (Upala, Guatuso y Los Chiles), fundados en su mayoría por migrantes nicaraguenses, San Carlos, y Sarapiquí (Rodríguez, 2001). Debido a la ausencia de vías de comunicación dentro de la región y con el Valle Central, situación que no empezaría a cambiar hasta la década de 1950, la vinculación comercial y económica de estos territorios fue en un primer momento con Nicaragua, principalmente en las regiones del norte, a través de actividades de extracción como la raicilla, la madera y el hule (León, 2015).

Con el agotamiento de la frontera agrícola a mediados del siglo XX y, posteriormente, debido a los esfuerzos del Estado por integrar a la región, esta condición empezó a transformarse, dando inicio a un proceso de desenclave que pretendía el acercamiento de la región con el Valle Central a través de la articulación de sus vías de comunicación (León, 2015). Sin embargo, aun cuando estos esfuerzos permitieron, de alguna manera, que estos frentes se encontraran, lo que en realidad ocurrió fue un acercamiento de la región, principalmente San Carlos, al Valle Central, más que entre los territorios que la componen (León, 2015). Esta situación ha contribuido a que incluso hoy los territorios que conforman la región demuestren cierta independencia, además de que se haya producido un debilitamiento de las relaciones con Nicaragua a través de las redes de intercambio fluviales que los caracterizaron históricamente.

Primero, San Carlos cumple la función de una semiperiferia entre los demás cantones de la RHN y el Valle Central. Segundo, debido a su previa y mayor integración al Valle Central, San Carlos concentra un conjunto de condiciones (infraestructura, instituciones públicas, etc.) que conducen hacia una cierta inercia de las actividades con mayor valor agregado hacia él y hacia niveles mayores de desarrollo humano. (León, 2015, p. 88)

De este modo, el proceso de articulación impulsado por el Estado parece haber fracasado en su esfuerzo por articular funcionalmente la región y, en su lugar, ha producido una relación de dependencia entre los ejes norte (Guatuso, Upala, Los Chiles) y Sarapiquí, en relación con el sur (San Carlos), al tiempo que la región padece la hegemonía de políticas de desarrollo uniformadoras provenientes del gobierno central que obvian sus dinámicas internas. En este marco, la RHN es concebida como un todo que se articula con el Valle Central mediante la producción de materias primas y alimentos, pero continúa siendo una región marginal que carece de intervenciones que promuevan el desarrollo de proyectos territorialmente diferenciados.

Todo esto es indicativo de que el discurso acerca de "lo rural" que pesa sobre la región no da cuenta de las complejidades que se entretejen en su interior. En el sentido más tradicional, se concibe la ruralidad en la región como asociada a una serie de características como su difícil acceso y deficiente comunicación, su economía eminentemente agrícola, su retraso con respecto a la ciudad, sus relaciones sociales tradicionales, entre otras que, aunque acertadas en algunos casos, proponen una mirada estática que justifica políticas de desarrollo orientadas a promover 
exclusivamente la producción de materia prima, antes que promover sus formas de vida, identidades, conocimientos, historias, etc. Es decir, dentro del mismo discurso sobre lo rural existe el sesgo de no atender la naturaleza misma de las particularidades que conforman este territorio.

Para un país como Costa Rica, que hasta hace poco ha empezado a pensarse regionalmente, repensar la región desde la diversidad de territorios y comunidades que la componen involucra romper con dos nociones importantes: en primer lugar, el llamado "vallecentralismo epistemológico" que hunde sus raíces en la construcción del Estado-Nación de finales del siglo XIX sobre la base de la diferenciación entre el Valle Central y la periferia, y cuya consecuencia ha sido una visión de país que tiende a invisibilizar las diferencias regionales $y$, en segundo lugar, con el discurso "sancarloscentrista" que piensa la RHN desde un centro, San Carlos, sin considerar las condiciones particulares que caracterizan a las demás regiones (León, 2015).

Esto es importante en una región que destaca entre las demás en el país por poseer un bajo índice de desarrollo social, así como la mayor cantidad de distritos con nivel muy bajo de todas las regiones del país (Zevallos, 2013). Desventaja que, en gran medida, es una consecuencia de la incapacidad de las políticas estatales de crear procesos de planificación acordes con las condiciones y realidades históricas y geográficas de la región. De acuerdo con Zevallos (2013), tan solo Upala posee 4 distritos con índices muy bajos (San José, Delicias, Dos Ríos y Yolillal), Los Chiles 3 (Los Chiles, El Amparo y San Jorge), Sarapiquí 3 (Puerto Viejo, Llanuras del Gaspar, Cureña), San Carlos 2 (Cutris y Pocosol) y Guatuso 1 (Cote). De ahí la importancia de procurar aproximaciones que superen la visión de región como un todo para empezar a dar cuenta de las múltiples realidades existentes dentro de este territorio. Al respecto, Angulo et al. (2010, p. 44) señalan lo siguiente:

En Costa Rica formalmente se distingue entre escuelas rurales y urbanas, pero esto no tiene mayores implicaciones prácticas desde la conducción del Ministerio de Educación. La estructura administrativa del Ministerio cuenta con una asesoría de escuelas unidocentes y un departamento de educación indígena, sin embargo, el quehacer de estas instancias no se articula en una política de Estado que contemple la especificidad de los procesos educativos que acontecen en el contexto rural o indígena.

Todo esto, aunado a "tendencias a la estandarización de la enseñanza para cumplir con los patrones internacionales", al "desarrollo de competencias de corte ... tecnocrático", y a la "desconcentración sin descentralizar decisiones y recursos", dificultan el trabajo educativo en la zona (Angulo et al., 2010, p. 46). Si bien es cierto existen buenos indicadores de cobertura y asistencia, algunos cantones como Los Chiles y Guatuso muestran diferencias importantes con respectos a los demás territorios -curiosamente los cantones en donde hay mayor presencia de población indígena y migrante-. De esta forma, entre los retos más importantes en materia de educación se encuentran el mejoramiento de la calidad de la educación, así como de los índices de finalización de primaria y secundaria. 
doi: http://dx.doi.org/10.15359/ree.22-2.18

URL: http://www.una.ac.cr/educare

CORREO: educare@una.cr

Los programas de estudio de primaria y secundaria no están adecuados a la dinámica actual; la oferta educativa no responde a las necesidades de las comunidades, hay una baja promoción en las pruebas estandarizadas. El servicio educativo actual es más teórico que práctico y se orienta más a la formación para un puesto de trabajo o un grado universitario y no hacia el emprendimiento. Es necesario entonces gestionar y ejecutar políticas públicas nacionales y regionales orientadas a la promoción de la sensibilidad social desde el sistema educativo para la inserción de los jóvenes en la vida productiva y el desarrollo de las capacidades emprendedoras y generadoras de MIPYMES. (Ministerio de Planificación Nacional y Política Económica [MIDEPLAN], 2014, p. 35)

De lo anterior, llama la atención el hecho de que los cantones que ostentan distritos con bajos índices de desarrollo son también los que poseen, a su vez, mayores deficiencias educativas. Asimismo, cabe mencionar que se trata de regiones que históricamente registran condiciones etnográficas particulares, debido a la presencia de población indígena y nicaragüense. Esta consideración es importante porque sugiere que las políticas hasta el momento no han sido justas con el perfil transfronterizo y multicultural que históricamente ha formado parte de las dinámicas económicos, culturales y sociales en la región.

En el discurso oficial, la integración y articulación de la inter y multiculturalidad está implícita para favorecer el desarrollo de lo local rural. No obstante, y teniendo en cuenta que, es en las zonas rurales donde en la mayoría de los casos, se encuentran ubicados los grupos étnicos que han sido objeto de mayor discriminación y quienes ven más vulnerados sus derechos, siguen perdurando la inequidad en la asignación de recursos. (Angulo et al., 2010, p. 148)

\section{Habitar un territorio transfronterizo}

Las zonas geográficas localizadas entre países vecinos, por lo general, son vistas como territorios con implicaciones geopolíticas para la defensa de los espacios nacionales. Pocas veces, sin embargo, se reconocen las dinámicas transfronterizas que conforman un tejido social y que dan como resultado un espacio de identidad cultural producto de la interconexión entre ambos países. De acuerdo con Morales y Castro (2002), en los espacios transfronterizos "se desarrollan una serie de dinámicas laborales, culturales, sociales y familiares, donde ... se crean y recrean nuevas conductas y situaciones sociales" (p. 20). En estos territorios, las personas migrantes experimentan, más que un proceso de asimilación social y cultural de los países destino, formas de vida que no necesariamente implican el rompimiento con sus lugares de origen. Esto se manifiesta mediante dinámicas binacionales a través de las cuales se construyen múltiples lazos e interacciones que vinculan a personas a través de las fronteras. 
El transnacionalismo produce una nueva práctica de las fronteras, cuyo efecto resultante es una nueva producción de lugares, y cuya manifestación más específica es la "transfrontericidad". ... A diferencia de otros sitios, lo particular de lo transfronterizo es el espacio de cruce, de redes de medios de transporte, de tránsito tanto formal como informal, de comercio y de redes sociales diversas; también es el cruce entre lo tradicional y lo posmoderno, tanto de ancestrales intercambios familiares y comunitarios, como de tecnologías y turismo. (Morales y Castro, p. 32)

Estas zonas transfronterizas generan la existencia de una "cultura fronteriza", entendida esta como "un sistema cultural particular que se define y emerge en un contexto geográfico y social específico, adoptando una identidad propia, cuyas expresiones y matices varían entre las distintas subregiones fronterizas" (Ojeda, 2009, 10). Se trata, entonces, de ir más allá de considerarlas como simples territorios en los que se cruzan dos nacionalidades -en la que una puede o no tener mayor influencia sobre la otra-, para dar paso a la posibilidad de un tercer espacio, un espacio intermedio, en el que ya no se trata de una separación, sino de una convivencia interétnica que crea "condiciones de mayor tolerancia y adaptación a los modos e ideas del 'otro lado', favoreciendo en mayor o menor medida el intercambio, la interacción e incluso la cooperación en algunas áreas entre los habitantes de los dos lados de la frontera" (Ojeda, 2009, p. 11).

... se invita a pensar la frontera como una región geográfico-social que abarca distintas subregiones, en la que se dan no sólo lazos económicos transfronterizos sino también vínculos sociales y demográficos entre las personas asentadas a ambos lados de la frontera, que viven y se reproducen social y demográficamente conforme a este complejo sistema social, el cual comprende rasgos culturales, sociales y normativos de los dos países, pero en un híbrido peculiar que denominamos como "Io fronterizo", y que se erige como un tercer orden social diferenciado de sus contrapartes nacionales. (Ojeda, 2009, p. 11)

Las comunidades fronterizas se encuentran en constante relación mediante actividades cotidianas que toman lugar a ambos lados de la línea fronteriza. Venta e intercambio de productos y servicios, acceso a la educación, así como el establecimiento de relaciones afectivas confluyen y se traslapan en un espacio en el que las personas que habitan estas comunidades migrantes "reconstruyen y adaptan el entorno de sus lugares de destino a semejanza de sus costumbres y tradiciones, en parte como resistencia a ser asimilados a las culturas locales de su nueva residencia" (Ojeda, 2009, p. 22). Las familias transfronterizas son un claro ejemplo de que los intercambios "no se limitan a cuestiones tangibles como objetos y remesas, ya que los intercambios se dan también en el plano de las ideas, los valores sociales y culturales, y de modo importante en la construcción de identidades (Besserer, 2003 y Kearney 2003, citados en Ojeda, 2009, p. 22). 
doi: http://dx.doi.org/10.15359/ree.22-2.18

URL: http://www.una.ac.cr/educare

CORREO: educare@una.cr

Este tipo de familias [transfronterizas] frecuentemente involucran a personas nacidas en cualquiera de los dos países, con estatus migratorios distintos, ciudadanos de uno u otro país, o bien con las dos nacionalidades, personas que viven en un lado de la frontera pero que trabajan en el otro, y personas que han sido socializadas en mayor o menor medida conforme a los marcos culturales y sociales de ambos países. (Ojeda, 2009, p. 13)

En este punto resulta importante establecer una distinción entre frontera, entendida como representación limítrofe, y zona fronteriza, como la percepción que tienen de su propia zona fronteriza aquellas personas que la habitan. Tal y como afirman Morales y Castro (2002), "aparte de la dimensión socio productiva, los componentes culturales, de género y socioafectivos conforman una argamasa ecosocial, compuesta por redes, símbolos, objetos e interacciones, sobre cuyo soporte se tejen nuevas identidades sociales y constituyen el germen de nuevas conformaciones socioterritoriales" (p. 39).

La emigración/inmigración produce modificaciones importantes en las comunidades de origen y de destino. Esas modificaciones se pueden examinar en la actividad socioproductiva, las dinámicas familiares, y la vida societal (dimensión organizativa, cultura y relaciones sociales). La migración produce también otras variaciones en las formas de relación entre comunidades de origen y comunidades receptoras, lo que produce una conexión e interdependencia dinámica: el desarrollo de un territorio o región se hace dependiente del otro y viceversa, en la medida en que entran en juego factores relacionados con la demanda y oferta de trabajo, redes de apoyo, remesas familiares, abastecimiento y consumo, etc. (Morales y Castro, 2002, pp. 62-63)

Si entendemos la identidad como un proceso dinámico, que se recrea individual y colectivamente, el fenómeno migratorio en los territorios fronterizos resulta clave para comprender las experiencias cotidianas desde las cuales personas de distintos orígenes aprenden a vivir juntas. En relación con esto, Sandoval (2008) señala la falta de precisión de términos tales como "adaptación" o "asimilación", e incluso "integración" para referirse a la manera en que se insertan los grupos migrantes a sus nuevos lugares de residencia. Todos estos conceptos, apunta Sandoval (2008), implican, ya sea la renuncia de los sujetos migrantes a su cultura, o el no reconocimiento del cambio que se produce en el proceso de reconocerse. Para luchar contra estas limitaciones, Sandoval (2008) recurre a Bhabha para referirse a lo que la autora denomina como un "en entre" (in between), que no es más que la posibilidad de un tercer espacio que reconoce la ambigüedad presente en las relaciones interculturales y que defiende la posibilidad de que exista un lugar en el que la relación entre dos culturas, por ejemplo, no sea ni lo uno ni lo otro, sino algo más. 
Políticamente, el tercer espacio ofrece la posibilidad de imaginar posiciones de sujeto que no se reduzcan a la asimilación, adaptación o integración a la sociedad a la que se ha llegado, como si esta no se estuviera haciendo continuamente, pese a las continuidades que también existen, ni una suerte de absolutismo étnico que reivindica los orígenes como algo inmutable, como si las personas que dejan sus países no cambiaran a lo largo del tiempo y el espacio, aunque también guarden recuerdos de sus orígenes. (Sandoval, 2008, p. 380)

A la luz de estas consideraciones, las zonas transfronterizas ofrecen una oportunidad para el examen de los procesos de construcción de identidades binacionales a través de la cual pueda surgir un discurso alternativo que supere las limitaciones de los nacionalismos y dé cuenta de las nuevas dinámicas que se gestan entre habitantes de estos territorios. Quienes habitan el norte de la RHN (Upala, Guatuso y Los Chiles), por ejemplo, han tenido una relación más cercana con Nicaragua que con la cabecera del cantón (San Carlos), la cual mira más hacia el Valle Central que a lo interior de la región (León, 2015).

En la región existe un alto número de mano de obra nicaragüense que trabaja en la recolección y cosecha de cultivos de exportación que predominan en la región, como la piña, la naranja y la caña de azúcar. Con el paso de los años, si bien existe un porcentaje importante de migración estacionaria, muchos de estos grupos nicaragüenses se han establecido definitivamente, formando sus familias y criándola en Costa Rica. Solo como ejemplo valga mencionar que “...más de un 30\% de la población de Pital es nicaragüense" (Lee, 2007, citado en León, 2015, p. 104). Sin embargo, incluso en el caso de aquellas personas ya nacionalizadas, su inclusión como parte de la comunidad nacional está sujeta a grandes contradicciones que las excluyen e invisibilizan dentro de las políticas públicas.

Una de las tareas pendientes continúa siendo concebir una política pública en materia de migración que parta del reconocimiento de la profunda interdependencia entre las personas migrantes, sus familiares y las comunidades de acogida. Miles de personas han encontrado empleo y residencia en Costa Rica, al tiempo que muchos y muchas costarricenses pueden desempeñarse en sus trabajos remunerados porque una persona nicaragüense cuida a sus hijos, hijas o familiares mayores. Algunas actividades económicas dependen estructuralmente de la participación de nicaragüenses, como es el caso de la construcción, la agricultura de exportación, la seguridad privada y, desde luego, el trabajo doméstico remunerado. (Sandoval, Brenes y Paniagua, 2012, p. 17)

Dos razones intensifican la migración de nicaragüenses a Costa Rica durante la segunda mitad del siglo XX: 1) a finales de la década de 1970, debido a los conflictos políticos del país y 2) los conflictos socioeconómicos en el marco de la globalización y la apertura económica y comercial de la década del 1980-1990 (Sandoval et al., 2012). Si bien la migración nicaragüense 
doi: http://dx.doi.org/10.15359/ree.22-2.18

URL: http://www.una.ac.cr/educare

CORREO: educare@una.cr

no es exclusiva a la RHN, sino que se extiende a nivel nacional, esta se posiciona como un tema cada vez más necesario en la región, si lo que se busca en comprender un territorio cuya dinámica social y económica trasciende las fronteras nacionales. "Este perfil transfronterizo debe ser tomado en cuenta, ya que se presenta como una de las pocas constantes a lo largo de la historia de la RHN y es un elemento fundamental para poder dar cuenta de las transformaciones sufridas por la región" (León, 2015, p. 45). En el caso de la población nicaragüense, además, significa luchar por resignificar, en primer lugar, la institucionalidad de un Estado que decide quién tiene derechos y quién no y, en segundo lugar, la superación del concepto de nacionalidad sobre el cual puedan construirse sociedades más justas en inclusivas para todos los seres humanos (Sandoval, 2015).

En este contexto, la dificultad que presenta el concepto de ciudadanía es que éste es establecido por políticas de Estado, las cuales, sobre todo en lo últimos años, han convertido prácticamente en sinónimos la condición de no tener documentos con ilegalidad y criminalidad. A su vez, esta relación imaginaria ha sido argumento para justificar las trabas para que las personas migrantes accedan a servicios básicos. (Sandoval et al., 2012, p. 14)

Desde hace algunos años, varios estudios han procurado atender el fenómeno de la inmigración nicaragüense en busca de procurar una sociedad más inclusiva para una población que sufre el peso de la discriminación y el rechazo por parte de un discurso que los ilegaliza y criminaliza. Si bien, como señala Sandoval (2008), la hostilidad y xenofobia que sufren los grupos nicaragüenses migrantes es una experiencia que merece ser abordada con atención, también es importante"acercarse a reconocer experiencias cotidianas desde las cuales personas de distintos orígenes aprenden a vivir juntas" (p. 379).

La RHN, donde habita una gran cantidad de familias binacionales, constituye un lugar desde el cual parecen cada vez más necesarios abordajes que procuren reconocer el espacio intermedio en el que se encuentran inmigrantes nicaragüenses, es decir, entre la asimilación del discurso hegemónico costarricense y la preservación de sus orígenes, para escuchar el sufrimiento que supone la exclusión en un país que no les incluye como parte del imaginario nacional. Desde el punto de vista de la educación, por ejemplo, ¿cómo incluir a esta población dentro de los programas educativos? Si bien a la fecha las investigaciones sobre migración nicaragüense han arrojado datos importantes, en realidad son pocas las acciones concretas que se realizan para promover discursos de paz y convivencia entre estos pueblos. Los niños, las niñas y las mujeres, por ejemplo, siguen permaneciendo al margen y poco se sabe sobre sus experiencias de vida en territorio costarricense. Esto parece fundamental, sobre todo en una región como la Centroamericana, en la que las condiciones de exclusión social se relacionan con la edad, la zona de residencia y el sexo como factores que determina las condiciones de vida de las personas (Programa Estado de la Nación en Desarrollo Humano Sostenible [Costa Rica], 2015). 
Por ello, una educación que reconozca y defienda la necesidad de abordar la RHN desde su perfil transfronterizo parece necesaria como una forma de generar experiencias de convivencia entre población extranjera y nacional, en un contexto en el que el tema se posiciona estratégicamente desde lo social, lo económico y lo cultural. Aunque a la fecha no existen datos que registren, por ejemplo, el número de estudiantes nicaragüenses en las escuelas y colegios de la zona, bien se sabe que en el cordón trasfronterizo los centros educativos costarricenses están más cercanos a la población nicaragüense que vive en la zona que la contraparte nicaragüense. Con todo, los programas educativos adolecen de aproximaciones que reconozcan los aportes culturales, así como el respeto a la identidad y la cultura del estudiantado migrante que forma parte del sistema educativo costarricense.

Parece necesario, en este sentido, realizar estudios dirigidos a caracterizar el fenómeno migratorio en los centros educativos de estos territorios, para promover procesos de aprendizaje que defiendan la comprensión y valoración entre las culturas, así como sus estilos de vida. Una educación rural intercultural es aquella que, además de promover los valores, la cotidianidad y la historia de la vida del campo, muestra una "preocupación por atender la multiculturalidad y lo pluriétnico, que se desenvuelve en gran medida en el contexto rural" (Angulo et al., 2010, p. 45). Se trata, en esencia, como bien apuntan Vidal et al. (2015, p. 30), de "manifestar a las niñas y los niños nicaragüenses que viven en Costa Rica que nos interesa conocer y acercarnos a su patria", como una forma de reconocerles el derecho que tienen de ser nicaragüenses, sin que por ello deban sufrir el peso de un sistema que les excluye y coloca entre los individuos más débiles de la cadena.

No obstante, ante la amplitud de definiciones acerca del concepto de interculturalidad que abunda en la actualidad, surge la necesidad de precisar cada vez más lo que se entiende por este concepto. Sobre todo, como señala Pérez (2009), si lo que se quiere es evitar el manejo indiscriminado del concepto para evitar caer con facilidad en marcos teóricos hegemónicos, olvidando el aporte de los países latinoamericanos asociados a los movimientos indígenas, decolonizadores $y$, en general, a la crítica en torno a la homogenización cultural heredada de los proyectos de Estado-nación.

... si bien la interculturalidad se menciona como fundamento de lo que se busca en una nueva sociedad, no hay acuerdos aún sobre lo que se entiende por ella, así como tampoco sobre el tipo y la profundidad de los cambios que deben hacerse. Está a debate el carácter nacional, plurinacional o multinacional de los Estados; el tipo de relaciones que debe haber entre los pueblos indios y la sociedad nacional; si la autonomía es o no una vía para el reconocimiento de derechos específicos; cuáles deben ser los modelos de desarrollo a seguir; el papel de los conocimientos indígenas en tal desarrollo; y cómo y por quién se decide el cambio o la permanencia cultural. (Pérez, 2009, p. 262) 
doi: http://dx.doi.org/10.15359/ree.22-2.18

URL: http://www.una.ac.cr/educare

CORREO: educare@una.cr

Para esta autora, el gran espectro de usos a los que ha sido sometido este concepto, así como las diferentes definiciones y propuestas, constituye uno de los principales retos en la tarea por asumir un verdadero proyecto intercultural, entendido este no solo como un principio que guía la convivencia entre sujetos culturalmente distintos, quienes aceptan y respetan sus diferencias, sino que, además, la valoran positivamente. Valorar positivamente significa en este caso "intentar situarse en el lugar del 'otro' para compartir sus creencias y valoraciones desde dentro" (p. 263), en lugar de solamente aspirar a ser capaz de "soportar la diferencia y aún la discrepancia en función de la convivencia como un valor importante, de modo que se tolera, aunque no se comparte" (Pérez, 2009, p. 263).

En este sentido, la interculturalidad surge de la necesidad de superar las limitaciones del llamado multiculturalismo, el cual, si bien propone construir relaciones sobre la base de la equidad, lo hace desde relaciones de tolerancia negativa, al fomentar la esencialización, el encapsulamiento y la segregación de las identidades, antes que relaciones simétricas entre culturas que favorezcan la creación de una verdadera cultura pública intercultural. Así, la interculturalidad no solo se propone como una salida para soportar la diferencia (tolerancia negativa), sino que, además, trata de construir formas de relacionarse que promuevan el respeto por las diferencias, al tiempo que las valora positivamente. En otras palabras, ambos conceptos apuntan a contrarrestar el modelo de nación que sustenta la homogenización cultural y lingüística, solo que, en el caso de la interculturalidad, existe la posibilidad de construir nuevas identidades producto del diálogo entre grupos culturalmente diversos. Es decir, se trata de sustituir el énfasis en los procesos de construcción de la diferencia identitaria y de las fronteras, para centrarse ahora en los puntos de intersección, contacto e intercambio que posibilitan la convivencia entre grupos (Pérez, 2009). De esta manera, "la interculturalidad proporciona un marco general para ... el deber ser social que debe procurar ... cierto tipo de relaciones asimétricas, justas y equitativas- [para regular las relaciones] e interacciones (la convivencia) entre los grupos culturalmente diferentes que habitan un mismo espacio histórico territorial o extraterritorial" (Pérez, 2009, pp. 282-283).

Esta distinción es importante en el marco de los procesos pedagógicos latinoamericanos, en donde el reto se centra muchas veces en revertir las condiciones de asimetría, exclusión y dominación de ciertos grupos, más que en posicionar una pedagogía intercultural que no solo cuestione los fundamentos monoculturales y monolinguísticos de los Estados nacionales, sino que además promueva relaciones interculturales positivas. Es aquí donde Pérez (2009) insiste en que la interculturalidad dentro del proceso educativo debe asumirse como una propuesta dialógica que trascienda la enseñanza de lenguas, en el caso de las poblaciones indígenas, para incluir un aprendizaje situado que incluya, además, el contexto social y cultural, así como la diversidad de población nacional (indígenas, afrodescendientes, extranjeros, etc.). Pero no solo eso, en tanto el sistema educativo se torne liberador, al permitir el encuentro intercultural, así también sucederá con las condiciones materiales y simbólicas sobre las que pueden construirse 
un nuevo orden social sustentado en la igualdad, la inclusión, el respeto, la solidaridad y, sobre todo, el diálogo. Sobre la base crítica de este proyecto político, "que supera el ámbito educativo y pedagógico, la interculturalidad actúa como el componente básico para proyectar la convivencia ética y la política de las futuras propuestas de la sociedad" (Pérez, 2009, p. 260).

Así las cosas, repensar la educación en los territorios rurales empieza por reconocer que la práctica educativa y la teoría muchas veces no se corresponden. $O$ se da el caso de que la teoría es más pobre que la práctica, como ocurre con los postulados acerca de la educación rural y la interculturalidad, o el caso opuesto de que la práctica ignora sus potencialidades de teorización. Los planteamientos que se proponen en este ensayo buscan argumentar acerca de la necesidad de abordar el tema de la educación rural intercultural desde el caso concreto de la $\mathrm{RHN}$, en donde el contacto entre distintos grupos humanos es una constante en las dinámicas cotidianas que caracterizan la región.

Asimismo, la RHN es un ejemplo claro del sesgo que pesa sobre las políticas nacionales que, al invisibilizar ciertos territorios y poblaciones, producen como resultado el rezago y la exclusión. En este sentido, se plantea una contextualización que permita comprender la región desde sus dinámicas históricas para facilitar el trabajo e implementación de políticas diferenciadas acordes a las necesidades de los distintos territorios y comunidades que conforman la región. Para ello se sugiere que la educación constituye una herramienta fundamental para promover el desarrollo de la región, siempre y cuando esta considere el contexto particular en el que se enmarca. Una educación que respete y responda a las necesidades particulares de los diversos territorios rurales constituye una salida a la estandarización de la educación, y a la defensa de los estilos de vida, valores, identidad e idioma de estas comunidades.

De esta manera, se plantea la necesidad de realizar esfuerzos dirigidos a los distintos grupos étnicos que componen la región, sobre todo a la población nicaragüense, la cual, a pesar de su gran protagonismo en las dinámicas económicas y culturales, hasta ahora sigue permaneciendo al margen del imaginario nacional. Las ideas de este ensayo buscan incentivar el trabajo en la región desde la comprensión de las diferencias que se tejen a lo interno; pero, sobre todo, cuestionar el concepto acerca de la nacionalidad de los derechos, lo cual parece fundamental, si lo que se quiere es imaginar una Costa Rica que favorezca cada vez más el reconocimiento de la diversidad y la inclusión social.

\section{Referencias}

Asamblea Legislativa de la República de Costa Rica (4 de julio de 2016). D.- El contenido de la República democrática de Costa Rica.- Ahora bien, el artículo $1^{\circ}$ de la Constitución Política empieza por señalar que: “Costa Rica es una República democrática, libre, independiente, multiétnica y pluricultural". Boletín Judicial, Año CXX, No 128, p. 8. Recuperado de http:// www.imprentanacional.go.cr/pub-boletin/2016/07/bol 0407 2016.pdf 
doi: http://dx.doi.org/10.15359/ree.22-2.18

URL: http://www.una.ac.cr/educare

CORREO: educare@una.cr

Angulo, L., Morera, D. y Torres, N. (2010). El proceso pedagógico de la escuela rural unidocente y multigrado centroamericana. Su evolución, condiciones actuales y perspectivas de desarrollo. San José, Costa Rica: El Atabal. Recuperado de https://issuu.com/educacionrural/docs/ libro el proceso pedagogico de la e

Echeverri, R. y Ribero, M. (2002). Nueva ruralidad. Visión del territorio en América Latina y el Caribe. Bogotá: IICA. Recuperado de http://repiica.iica.int/docs/B0536e/B0536e.pdf

León, A. (2015). Desarrollo geográfico desigual en Costa Rica. El Ajuste estructural visto desde la Región Huetar Norte (1985-2005). San José, Costa Rica: Editorial UCR.

Méndez, M. V. (2015). El derecho a la educación y las edades mínimas de protección legal en Centroamérica. Heredia, Costa Rica: EUNA.

Ministerio de Planificación Nacional y Política Económica. (2014). Región Huertar Norte. Plan de Desarrollo 2030. San José, Costa Rica: MIDEPLAN. Recuperado de https://documentos. mideplan.go.cr/alfresco/d/d/workspace/SpacesStore/72e8292f-97f9-465c-a5edc2c4b442a55c/Region\%20Huetar\%20Norte.pdf?guest=true

Mora, J. (2013). Desarrollo rural y ciudadanía social: Territorios, instituciones y actores locales. San José, Costa Rica: Euned. Recuperado de https://mpra.ub.uni-muenchen.de/46671/1/ MPRA_paper_46671.pdf

Morales, A. (2007). La diáspora de la posguerra. Regionalismo de los migrantes y dinámicas territoriales en América Central. San José, Costa Rica: Flacso. Recuperado de http://unpan1. un.org/intradoc/groups/public/documents/icap/unpan028349.pdf

Morales, A. y Castro, C. (2002). Redes transfronterizas: Sociedad, empleo y migración entre Nicaragua y Costa Rica. San José, Costa Rica: Flacso. Recuperado de http://www.acnur.org/ t3/fileadmin/Documentos/Publicaciones/2008/6308.pdf?view=1

Ojeda, N. (2009). Reflexiones acerca de las familias transfronterizas y las familias transnacionales entre México y Estados Unidos. Frontera Norte, 21(42), 8-30. Recuperado de http://www. scielo.org.mx/scielo.php?script=sci arttext\&pid=S0187-73722009000200001

Pérez, M. L. (2009). ¿De qué hablamos cuando nos referimos a lo intercultural? Reflexiones sobre su origen, contenidos, aportaciones y limitaciones. En L. R. Valladares, M. L. Pérez y M. Zárate (Coords.), Estados plurales: Los retos de la diversidad (pp. 251-288). México: Editorial UAM. Recuperado de http://deas.inah.gob.mx/images/contenido/maya/dequehablamos.pdf

Programa Estado de la Nación en Desarrollo Humano Sostenible (Costa Rica). (2015). Exclusión educativa y laboral de la población de 15 a 24 años en Centroamérica. Proyecto Estado de la Región. San José, Costa Rica: Prolitsa. Recuperado de http://ciases.org.ni/wp-content/ uploads/2016/06/Aportes-15-Exclusiones-jovenes-CA-vf.pdf 
Rodríguez, F. (2001). Región, identidad y cultura. San José, Costa Rica: Ediciones Perro Azul.

Sandoval, C. (2008). Algunos retos de la investigación en migraciones. Reflexiones a partir de Costa Rica. En C. Sandoval (Ed.), El mito roto. Inmigración y emigración en Costa Rica (373383). San José, Costa Rica: Editorial UCR.

Sandoval C., Brenes, M. y Paniagua L. (2012). La dignidad vale mucho: Mujeres nicaragüenses forjan derechos en Costa Rica. San José, Costa Rica: Editorial UCR.

Sandoval C. (2015). No más muros. Exclusión y migración forzada en Centroamérica. San José, Costa Rica: Editorial UCR. Recuperado de http://www.cpalsocial.org/documentos/190.pdf

Vidal, M., Torres, N., Cerdas, Y. y Vargas, M. (2015). Comunidades rurales aprendientes: Nuevas rutas en la educación continua. Una educación continua donde aprendimos a sentir, pensar, vivir, compartir, hacer, decir... San José, Cosa Rica: El Atabal.

Zevallos, E. (2013). Agenda de competitividad para la Región Huetar Norte: Caracterización socioeconómica de la Región Huetar Norte. San José, Costa Rica: MIDEPLAN. 